\title{
Prevalence and genotype distribution of hepatitis $C$ virus within hemodialysis units in Thailand: role of HCV core antigen in the assessment of viremia
}

Natthaya Chuaypen', Apichaya Khlaiphuengsin', Thaninee Prasoppokakorn², Paweena Susantitaphong ${ }^{3}$, Wisit Prasithsirikul ${ }^{4}$, Anchalee Avihingsanon ${ }^{5}$, Pisit Tangkijvanich ${ }^{1^{*}}$ and Kearkiat Praditpornsilpa ${ }^{3^{*}}$

\begin{abstract}
Background: Individuals with end-stage renal disease have a higher risk of hepatitis C virus (HCV) acquisition during long-term hemodialysis (HD). Our report was designed to investigate HCV prevalence and genotype, in addition to the clinical use of HCV core antigen (HCVcAg), within multiple HD facilities in Thailand.

Methods: This cross-sectional report was investigated between January and June 2019. HCV infection was assessed by anti-HCV and confirmed active infection by measuring HCV RNA and HCVCAg. HCV genotype was determined by phylogenetic analysis using nucleotide sequences of NS5B region.

Results: Overall, 140 of 3,305 (4.2\%) patients in 15 dialysis centers had anti-HCV positive. Among them, HCV RNA was further assessed in 93 patients and was detectable in 59 (63.4\%) persons. Considering HCV viremia, HCVcAg measurement exhibited high accuracy (96.8\%), sensitivity (94.9\%) and specificity (100\%) in comparison with HCV RNA testing. Moreover, individuals infected with HCV received a longer duration of dialysis vintage when compared to anti-HCV negative controls. The major sub-genotypes were $1 \mathrm{a}, 1 \mathrm{~b}, 3 \mathrm{a}, 3 \mathrm{~b}, 6 \mathrm{f}$ and $6 \mathrm{n}$. Regarding phylogenetic analysis, there were 7 clusters of isolates with high sequence homology affecting 17 individuals, indicating possible HCV transmission within the same HD centers.

Conclusions: HCV frequency and common sub-genotypes in HD centers were different from those found in the Thai general population. HCVcAg might be an alternate testing for viremia within resource-limited countries. Enhanced preventive practices, dialyzer reuse policy and better access to antiviral therapy are crucial for HCV micro-elimination within HD facilities.
\end{abstract}

Keywords: HCV, Genotype, Core antigen, Transmission, Hemodialysis, Dialyzer reuse

*Correspondence: pisittkvn@yahoo.com; kearkiat@hotmail.com ${ }^{1}$ Center of Excellence in Hepatitis and Liver Cancer, Department of Biochemistry, Faculty of Medicine, Chulalongkorn University, Bangkok 10330, Thailand

${ }^{3}$ Division of Nephrology, Department of Medicine, Faculty of Medicine, Chulalongkorn University and King Chulalongkorn Memorial Hospital, Bangkok, Thailand

Full list of author information is available at the end of the article

\section{Background}

Hepatitis $\mathrm{C}$ virus (HCV) infection is an important global health problem, with approximately 71 million people are chronically infected with the virus [1]. HCV has been classified into seven major genotypes, each containing a variable number of closely related subtypes [2]. In Thailand, the prevalence of $\mathrm{HCV}$ in the general population is approximately $1 \%$, with the most common genotypes are 
genotype 3 (HCV-3), followed by genotype 1 (HCV-1) and genotype 6 (HCV-6) [3]. Chronic HCV infection is a major etiological cause of chronic hepatitis, cirrhosis, hepatic decompensation and hepatocellular carcinoma (HCC). Moreover, several extrahepatic manifestations have been shown to be associated to chronic HCV infection including insulin resistance, type 2 diabetes, cardiovascular diseases and chronic kidney disease (CKD) [4]. A meta-analysis has indicated that chronic $\mathrm{HCV}$ infection is linked to $50 \%$ increased risk of proteinuria and 40\% increased incidence of CKD [5]. Moreover, HCV-infected patients with CKD tend to have an accelerated rate of renal impairment leading to progressive end-stage renal disease (ESRD) and increased relatedcomplications [6]. With the advance of interferon-free direct-acting antivirals (DAAs), HCV therapy has been substantially changed as difficult-to-treat populations including patients with late-stage CKD could achieve sustained virological response (SVR) rates over 90\% [7]. Current data have demonstrated that successful $\mathrm{HCV}$ antiviral therapy not only reduces the risk of cirrhosis and $\mathrm{HCC}$ but also improves extrahepatic manifestations of HCV infection [7].

As HCV transmission occurs primarily through bloodto-blood contact, patients with CKD stages 5 undergoing maintenance hemodialysis (HD) have an increased risk of HCV infection. Despite a trend toward lower HCV prevalence among general populations, the infected rate in patients with late-stage CKD continues to be a major concern [6]. Such higher prevalence has been linked to an increased exposure for $\mathrm{HCV}$ acquisition including frequent invasive medical procedures and nosocomial transmission within HD units [8]. Moreover, the prevalence of $\mathrm{HCV}$ infection in patients with CKD undergoing HD differ significantly across global regions, ranging from approximately $1.5-30 \%$, and $5-40 \%$, in developed and developing countries, respectively [9]. Additionally, isolated small-scale HCV outbreaks ( $\geq 2$ patients) in HD units still occur sporadically worldwide even with available specific infection control guidelines [8]. These data highlight the need for better assessment of the infection, improved infection control measures and increased access to antiviral treatments to prevent potential spreading of HCV in HD settings.

According to the Kidney Disease: Improving Global Outcome (KDIGO) guideline [10], it is recommended that all patients with CKD should undergo testing for $\mathrm{HCV}$ infection before initiating dialysis. In this context, screening of anti-HCV antibodies by immunoassays and confirmation of active HCV infection by nucleic acid testing (NAT) are necessary. Moreover, patients in dialysis units should be regularly tested with serum alanine aminotransferase (ALT) monthly and anti-HCV antibodies or NAT for HCV RNA semi-annually. Recently, serum $\mathrm{HCV}$ core antigen $(\mathrm{HCV} \mathrm{cAg})$ quantification has emerged as an alternative assay to $\mathrm{HCV}$ RNA quantification because of its rapidity, being less expensive and more feasibility in resource-limited settings [11]. In addition, a recent report has shown that $\mathrm{HCVcAg}$ measurement is cost-saving and could potentially replace HCV RNA for detecting $\mathrm{HCV}$ viremia [12]. To date, data regarding the utility of serum HCVcAg in monitoring active $\mathrm{HCV}$ infection in patients with CKD are inadequate.

The aims of this study were to investigate the prevalence and genotype distribution of $\mathrm{HCV}$ in patients undergoing long-term HD across several centers in Thailand. The possibility of patient-to-patient transmission of $\mathrm{HCV}$ within the same HD facilities was also determined using phylogenetic analysis. In addition, this study evaluated the usefulness of serum $\mathrm{HCVcAg}$ as a potential replacement of HCV RNA in assessing $\mathrm{HCV}$ viremia. Finally, we proposed a simple algorithm for the detection and monitoring of $\mathrm{HCV}$ infection among patients undergoing HD.

\section{Methods \\ Participants}

A cross-sectional study was performed among patients undergoing chronic HD at 15 centers in Bangkok and other provinces from January to June 2019. Screening for $\mathrm{HCV}$ infection in these centers was carried out using anti-HCV antibody. Patients with positive results in the screening assays were invited to participate in the study and further assessed for $\mathrm{HCV}$ viremia and molecular analysis. Patients co-infected with hepatitis B virus (HBV) or human immunodeficiency virus (HIV) were excluded.

\section{Laboratory assays}

Serum aspartate aminotransferase (AST), alanine aminotransferase (ALT) and other biochemical tests were evaluated by standard methods. AST/platelet ratio index (APRI) as a non-invasive serum marker for liver fibrosis was calculated by the following formula: (AST/upper limit of normal considered as $40 \mathrm{IU} / \mathrm{L}$ )/platelet count $\left(10^{9} / \mathrm{L}\right) \times 100$. In a meta-analysis, an APRI score greater than 1.0 had a sensitivity and specificity of $76 \%$ and $72 \%$, respectively for predicting cirrhosis. In addition, an APRI score greater than 0.7 had a sensitivity of $77 \%$ and specificity of $72 \%$ for predicting significant fibrosis [13].

Anti-HCV antibody was tested with a third-generation chemiluminescent microparticle immunoassay (CMIA, ARCHITECT system, Abbott Diagnostics, Wiesbaden, Germany). HCV RNA quantification was performed using real-time quantitative reverse-transcription polymerase chain reaction (RT-PCR) (Abbott Molecular Inc. 
Des Plaines, IL, USA) in accordance with the manufacturer's instructions. The lower and upper detection limits of the assay were $<12 \mathrm{IU} / \mathrm{mL}$ and $100,000,000 \mathrm{IU} / \mathrm{mL}$, respectively. Serum $\mathrm{HCVcAg}$ quantification was analyzed by a two-step CMIA (Abbott Diagnostics, Tokyo, Japan). The test allows the determination of $\mathrm{HCVcAg}$ in a linear range 3-20,000 femtomoles/liter (fmol/L). Samples with concentrations between 3 and $10 \mathrm{fmol} / \mathrm{L}$ were defined as 'grey zone' and were re-examined in duplicate as manufacturer recommendations [14]. If at least one duplicate test was positive or in grey-zone, the sample was considered as positive test.

\section{HCV genotyping}

HCV genotyping was performed as previously described [3]. Briefly, HCV RNA was extracted from anti-HCV positive serum samples by guanidine thiocyanate method. cDNAs were generated from viral RNA by using RevertAid first strand cDNA synthesis kit (Thermo Scientific) according to the manufacturer's instructions. Genotype was determined based on the nucleotide sequence of the NS5B region $[15,16]$. Nested PCR of the NS5B region was performed by using primer pairs of NS5B_F1 and NS5B_R1 in the first round and NS5B_F2 and NS5BR2 were used in the second round. First and second amplification reactions were as followed: pre-incubation at $94{ }^{\circ} \mathrm{C}$ for $3 \mathrm{~min}$., 40 cycles of denaturation at $94{ }^{\circ} \mathrm{C}$ for $1 \mathrm{~min}$., annealing at $52{ }^{\circ} \mathrm{C}$ for $1 \mathrm{~min}$., extension at $72{ }^{\circ} \mathrm{C}$ for $1.30 \mathrm{~min}$. and a final extension step at $72{ }^{\circ} \mathrm{C}$ for $7 \mathrm{~min}$. The sequences were edited using Bio-Edit (v.7.2.5) (Ibis Therapeutics, Carlsbad, CA) and similarity between sequences was examined by the BLASTN program (http://www.ncbi.nlm.nih.gov).

\section{Phylogenetic analysis}

Multiple alignments were performed using CLUSTALW (Bio-Edit version 7.2.5 software) and the phylogenic trees of NS5B gene was constructed with matrix of pairwise distances estimated under the maximum-likelihood method based on the general time-reversible (GTR) substitution, gamma-distribution (G) and invariant sites(I); GTR + G + I model [17] by using MEGA X 10.2.1 software. The statistical analysis of constructed trees was performed by 1,000 replicates bootstrap test to confirm the reliability of the phylogenetic tree. The transmission clusters were identified at a branch support threshold of 0.7 and a genetic distance threshold of 0.045 using Cluster Picker software as described previously [18].

The reference sequences of $\mathrm{HCV}$ were retrieved from GenBank as follows: genotype 1a (D10749), genotype 1b (D90208, M58335), genotype 1c (D14853), genotype 2a (AB047639, D00944), genotype 2b (AB030907, D10988), genotype 2c (D50409), genotype 3a (D17763, D28917), genotype 3b (D49374), genotype 5a (AF064490), genotype 6a (AY859526), genotype 6b (D84262), genotype 6c (EF424629), genotype 6d (D84263), genotype 6e (DQ314805), genotype 6f (DQ835760), genotype $6 \mathrm{~g}$ (D63822), genotype $6 \mathrm{~h}$ (D84265), genotype 6i (DQ835770), genotype 6j (DQ835769), genotype $6 \mathrm{k}$ (D84264), genotype $6 \mathrm{~m}$ (DQ835767), genotype 6n (DQ278894, DQ835768), genotype 6r (EU408328), genotype 6t (EF632071, EU246939), genotype 6u (EU246940, EU408330, EU408332), genotype 6v (EU158186, EU798760), genotype 6w (DQ278892, EU643834), genotype $6 \mathrm{~s}$ (EU408329).

The nucleotide sequences of NS5B gene have been submitted to the GenBank database under accession numbers MT428260-MT428322.

\section{Ethics statement}

All patients gave their informed written consent. The study was reviewed and approved by the Institutional Review Board, Faculty of Medicine, Chulalongkorn University. The study was performed in accordance with Declaration of Helsinki for the participation of human individuals. Information regarding demographic data were collected using a standardized questionnaire.

\section{Statistical analyses}

Data were expressed as percentages or median with interquartile range (IQR). Comparisons between groups were analyzed by the $\chi^{2}$ or Fisher's exact test for categorical variables and by two-sample $t$ tests for continuous variables as appropriate. Correlations between parameters were assessed by the Spearman's rank test. Sensitivity, specificity, positive predictive value (PPV), negative predictive value (NPV) and diagnostic accuracy were calculated in accordance with standard methods. $P$ value $<0.05$ was considered as a statistical significance. Statistical analyses were performed by the IBM SPSS software version 23.0 (IBM, Chicago, IL, USA).

\section{Results}

\section{Characteristics of the Participants}

Among 3,305 patients who were on chronic HD in the participating centers during the time of the study, 140 (4.2\%) individuals were tested positive for anti-HCV antibodies. Among these, 93 (66.4\%) patients accepted to participate in the study. The median age of these 93 patients was 54.0 years with the majority were male (67.7\%). To compare clinical characteristics and possible risk factors of $\mathrm{HCV}$ infection, additional 93 subjects with matched age and gender, randomly selected from the pool of ESRD patients who had anti-HCV negative, were used as the control group (Table 1). Compared to the control group, patients with anti-HCV positive had 
Table 1 The characteristics of patient in this study

\begin{tabular}{|c|c|c|c|c|}
\hline & Total $(n=186)$ & $\begin{array}{l}\text { Patients with anti-HCV positive } \\
(\mathrm{n}=93)\end{array}$ & $\begin{array}{l}\text { Patients with anti-HCV negative } \\
(\mathrm{n}=93)\end{array}$ & $P$ \\
\hline Age (year) & $53.3(44.8-62.3)$ & $54.0(44.8-62.6)$ & $52.7(45.0-62.0)$ & 0.415 \\
\hline Sex & & & & 0.358 \\
\hline Male & $120(64.5)$ & $63(67.7)$ & $57(61.3)$ & \\
\hline Female & $66(35.5)$ & $30(32.3)$ & $36(38.7)$ & \\
\hline BMI $\left(\mathrm{kg} / \mathrm{m}^{2}\right)$ & $22.0(20.1-24.6)$ & $22.1(19.3-24.5)$ & $21.9(20.2-24.8)$ & 0.206 \\
\hline IDU & $20(10.8)$ & $15(16.1)$ & $5(5.4)$ & $0.031^{*}$ \\
\hline MSM & $6(3.2)$ & $2(2.2)$ & $4(4.3)$ & 0.682 \\
\hline Dialysis vintage (years) & $7.0(4.0-10.3)$ & $7.1(4.0-13.0)$ & $5.1(4.0-9.0)$ & $0.013^{*}$ \\
\hline $\mathrm{ALT}(\mathrm{U} / \mathrm{L})$ & $16.0(11.3-23.0)$ & $19.5(14.0-27.5)$ & $14.0(11.0-21.0)$ & $0.001 *$ \\
\hline AST (U/L) & $18.5(13.0-26.3)$ & $24(17.0-32.5)$ & $16(12.0-21.0)$ & $<0.001^{*}$ \\
\hline $\mathrm{Cr}(\mathrm{mg} / \mathrm{dL})$ & $9.2(7.2-11.2)$ & $9.1(6.9-11.1)$ & $9.3(7.2-11.4)$ & 0.655 \\
\hline APRI & $0.23(0.16-0.32)$ & $0.29(0.20-0.42)$ & $0.20(0.14-0.29)$ & $<0.001^{*}$ \\
\hline
\end{tabular}

Data are expressed as median (IQR) or $n(\%)$, as appropriate; ${ }^{*} P<0.05$

had a significantly longer dialysis vintage (median of 7.1 years vs. 5.1 years for the anti-HCV negative group, $P=0.013)$. In addition, patients with anti-HCV positive had increased AST and ALT levels, as well as significantly higher APRI scores, representing higher degree of liver fibrosis compared with the control group. Of note, there were $9(9.7 \%)$ and 7 (7.5\%) patients with anti-HCV positive, who had an APRI score greater than 0.7 and 1.0, respectively. In contrast, no patients in the anti-HCV negative group had an APRI score greater than 0.7.

\section{HCV RNA and HCVCAg testing}

Among patients with anti-HCV positivity, HCV RNA quantification was further performed. Fifty-nine of 93 (63.4\%) patients displayed active $\mathrm{HCV}$ infection with the median HCV RNA level of $5.7 \log _{10} \mathrm{IU} / \mathrm{mL}$ (range, 2.3-7.5 $\left.\log _{10} \mathrm{IU} / \mathrm{mL}\right)$, while $34(36.6 \%)$ individuals had undetectable viral load (HCV RNA $<12 \mathrm{IU} / \mathrm{mL}$ ). Clinical characteristics and risk factors between these groups were compared as shown in Table 2 . There was no significant difference between groups in terms of age, gender distribution, GFR and APRI score. However, patients with viremia exhibited significantly higher AST level compared with those with undetectable HCV RNA.

To evaluate the usefulness of serum $\mathrm{HCVcAg}$, serum samples of all 93 patients with anti-HCV positive were tested for serum HCV RNA and HCVcAg in parallel. Overall, $\log _{10} \mathrm{HCVcAg}$ levels were strongly correlated with corresponding $\log _{10} \mathrm{HCV}$ RNA levels $(\mathrm{r}=0.956$, $P<0.001)$. Moreover, there was a high concordance of

Table 2 The characteristics of patients with anti-HCV positive

\begin{tabular}{|c|c|c|c|c|}
\hline & Total $(n=93)$ & $\begin{array}{l}\text { Patients with HCV RNA positive } \\
(n=59)\end{array}$ & $\begin{array}{l}\text { Patients with HCV RNA negative } \\
(\mathrm{n}=34)\end{array}$ & $P$ \\
\hline Age (year) & $54.0(44.8-62.6)$ & $56.3(47.5-63.6)$ & $53.2(43.0-59.9)$ & 0.153 \\
\hline Sex & & & & 0.634 \\
\hline Male & $63(67.7)$ & $41(69.5)$ & $22(64.7)$ & \\
\hline Female & $30(32.3)$ & $18(30.5)$ & $12(35.5)$ & \\
\hline BMI $\left(\mathrm{kg} / \mathrm{m}^{2}\right)$ & $22.1(19.3-24.5)$ & $21.8(18.5-23.8)$ & $22.5(19.8-25.8)$ & 0.307 \\
\hline IDU & $15(16.1)$ & $11(18.6)$ & $4(11.8)$ & 0.560 \\
\hline MSM & $2(2.2)$ & $1(1.7)$ & $1(2.9)$ & 1.000 \\
\hline Dialysis vintage & $7.0(4.0-13.0)$ & $7.0(5.0-13.0)$ & $7.5(3.8-13.0)$ & 0.575 \\
\hline $\operatorname{ALT}(\mathrm{U} / \mathrm{L})$ & $19.5(14.0-27.5)$ & $22(16-38)$ & $17(13-23.5)$ & 0.072 \\
\hline AST (U/L) & $24(17-32.5)$ & $26.5(17.3-36.8)$ & $20(14-26.5)$ & $0.039^{*}$ \\
\hline $\mathrm{Cr}(\mathrm{mg} / \mathrm{dL})$ & $9.2(6.9-11.1)$ & $9.4(6.7-11.1)$ & $8.7(7.3-11.3)$ & 0.597 \\
\hline APRI & $0.29(0.20-0.42)$ & $0.31(0.22-0.61)$ & $0.26(0.18-0.33)$ & 0.122 \\
\hline
\end{tabular}


detectable or undetectable $\mathrm{HCV}$ cAg and $\mathrm{HCV}$ RNA (Table 3). In our cohort, 3 patients with detectable $\mathrm{HCV}$ RNA were negative for $\mathrm{HCV} c A g$, all of whom had low viral load (HCV RNA $<3,000 \mathrm{IU} / \mathrm{ml}$ ). Using HCV RNA as the gold standard method, $\mathrm{HCVcAg}$ demonstrated a high sensitivity (94.9\%) specificity (100\%), PPV (100\%), NPV $(91.9 \%)$ and diagnostic accuracy $(96.8 \%)$.

\section{HCV genotypes and phylogenetic analysis}

A total of 56 out of 59 (94.9\%) sera from patients with HCV RNA positive were available for HCV genotyping analysis. Our result demonstrated that there were 4 HCV genotypes and 7 sub-genotypes distribution. The samples were distributed as follows: twenty-five (44.6\%) isolated from these patients belonged to $\mathrm{HCV}-1$ [HCV sub-genotype 1a (HCV-1a); 44.0\%, 11/25 and HCV-1b; $56.0 \%, 14 / 25)$ ], while $21(37.5 \%)$ patients were infected with HCV-3 (HCV-3a; 71.4\%, 15/21 and HCV-3b; 28.6\%, $6 / 21)$. In addition, $9(16.1 \%)$ patients were infected with HCV-6 (HCV-6f; 55.6\%, 5/9 and HCV-6n; 44.4\%) and 1 $(1.8 \%)$ individual was infected with HCV-2b.

To address patient-to-patient transmission, nucleotide sequences obtained in this study were aligned with the sequences deposited in GenBank for HCV genotypes. Phylogenetic tree and transmission clusters were also constructed (Fig. 1). The Cluster Picker identified 7 potential transmission clusters of patients undergoing maintenance HD in separate dialysis centers, which defined as monophyletic clusters of two or more patients' sequence with more than $70 \%$ bootstrap support and at genetic threshold of $4.5 \%$. In this study, we found $30.4 \%$ of patients $(17 / 56)$ were suspected to be infected with HCV by using the same HD machines from 5 different HD centers. In center 1 , two patients were infected with HCV-6n and clustered to each other (cluster 4) with a bootstrap value of 100 . Two patients were infected with $\mathrm{HCV}-6 \mathrm{f}$ and clustered with

Table 3 Comparison between HCVcAg and HCV RNA assays

\begin{tabular}{lcccc}
\hline HCVcAg & HCV RNA & & Total \\
\cline { 2 - 3 } & Positive & Negative & \\
\hline Positive & 56 & 0 & 56 \\
Negative & 3 & 34 & 37 \\
Total & 59 & 34 & 93 \\
\hline
\end{tabular}

bootstrap value of 98 (cluster 5) and two patients were infected with HCV-3b and clustered with bootstrap value of 100 (cluster 2). In center 2, Two patients were infected with $\mathrm{HCV}-1 \mathrm{~b}$ and clustered with bootstrap value of 100 (cluster 6) and three patients were infected with $\mathrm{HCV}$ 3a and clustered with bootstrap value of 98 (cluster 3). In center 3, two patients were infected with HCV-1a and clustered with bootstrap value of 91 (cluster 7 ). In center 4, two patients were infected with $\mathrm{HCV}-1 \mathrm{~b}$ and clustered with bootstrap value of 82 (cluster 6). In center 5 , two patients were infected with HCV-3b and clustered with bootstrap value of 84 (cluster 1). The phylogenetic tree indicated high homology and close clustering of HCV quasispecies among these cases, patient-to-patient transmission of $\mathrm{HCV}$ was highly suggestive in the respective facilities.

\section{Discussion}

Chronic HCV infection constitutes a health issue worldwide due to its adverse impact on quality of life and survival of infected individuals in terms of progressive liver disease and extrahepatic manifestations including CKD [1]. The burden of HCV infection among patients with ESRD undergoing dialysis varies considerably among dialysis units worldwide and its prevalence remains higher than in the general population [5]. Currently, there are limited data regarding the molecular epidemiology of $\mathrm{HCV}$ among patients undergoing long-term dialysis in Thailand. In this multicenter study, we showed that the prevalence of anti$\mathrm{HCV}$ antibodies among patients with ESRD was approximately $4.2 \%$, which appeared to be similar to the report of the Renal Registry of Thailand (4\%)[19] but was approximately 3 times higher than in the Thai general population with the same age group (1.5\%) [3]. Of note, our seroprevalence rate was comparable to those reports in the developed world (1.5\%-30\%), but lower than those found in other developing countries with prevalence rates of $5-40 \%$ [9]. These data might indicate the different epidemiological characteristics of the respective general populations, as well as various factors that might be associated with inadequate control processes against the infection within dialysis facilities.

Identifying $\mathrm{HCV}$ genotype has clinical significance in relation to disease manifestations and treatment outcome. In this study, several HCV genotypes including HCV$1 a,-1 b,-2 b,-3 a,-3 b$, and -6 variants were identified. Of note, the observed predominance of $\mathrm{HCV}-1(\mathrm{HCV}-1 \mathrm{a} / 1 \mathrm{~b})$

(See figure on next page.)

Fig. 1 Phylogenetic tree of HCV NS5B sequence based on maximum likelihood using MEGA X version 10.2.1 under maximum-likelihood method with 1,000 replicate bootstrap under the GTR $+\mathrm{G}+$ I model. Cluster Picker software identified 7 phylogenic clusters at a branch support threshold of 0.7 and a genetic distance threshold of 0.045 (green branch line and green alphabet), which represented patient-to-patient transmission clusters (17 patients are shown by red circle). Red right square brackets represent each hemodialysis center. Scale bars indicate nucleotide substitutions per site 


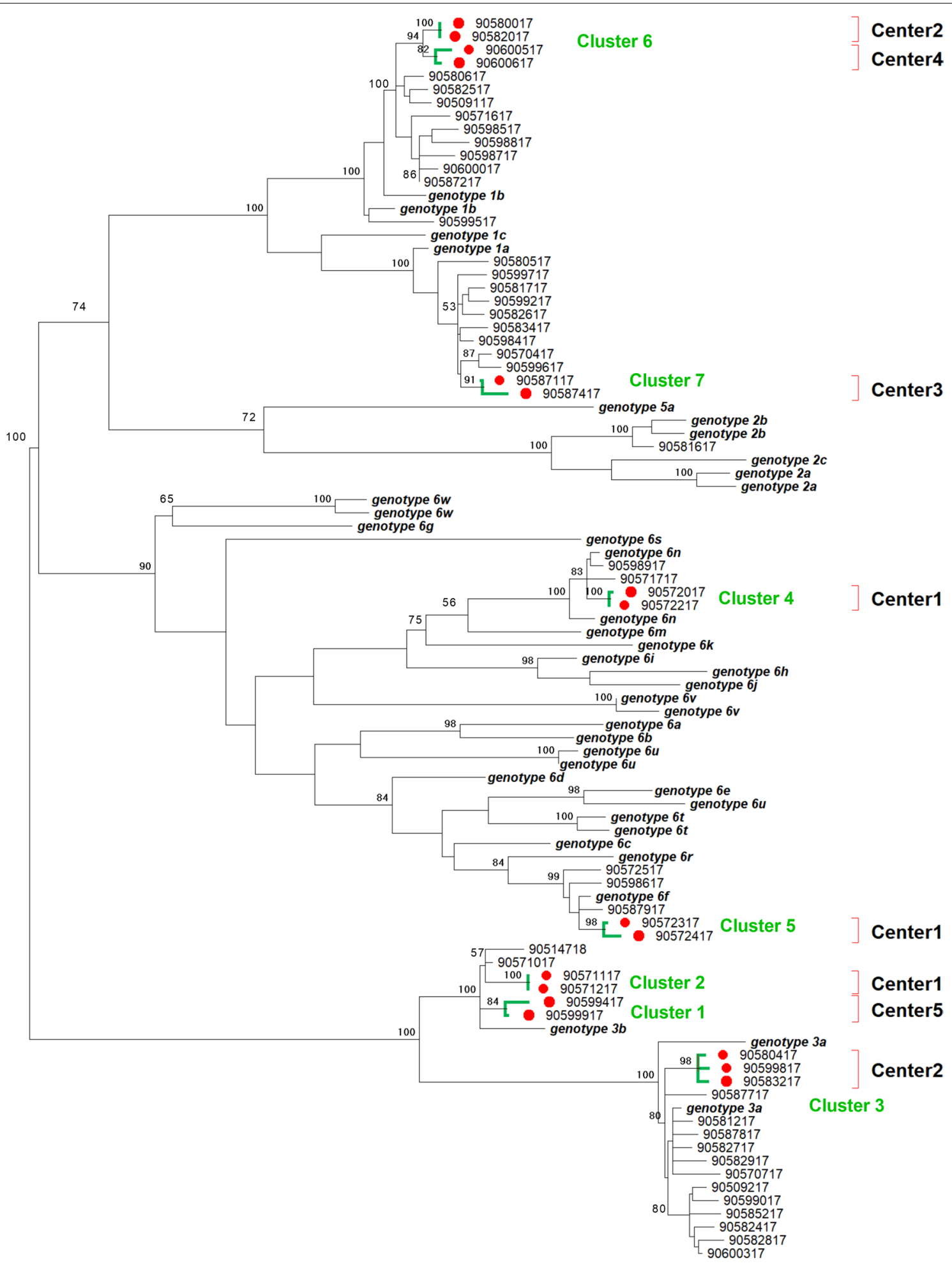


differed, to some extent, from the Thai general population that the most common genotype is HCV-3, followed by HCV-1 and HCV-6. In fact, our molecular epidemiological studies showed that HCV-3a continued to be the most common genotype in Thailand ranging from 43.5 to $51.5 \%$ over the past decade $[3,20]$. Interestingly, high prevalence of HCV-1 in our study was in line with previous reports from several dialysis centers in Asian, European and South American countries [21]. The mechanism by which HCV-1 typically prevails over other HCV genotypes among patients with ESRD is not clear and needs further investigation. Also, it should be mentioned that a high proportion of HCV-6 variants (approximately 20\%) in this report was similar to the observation among the Thai general population. Indeed, HCV-6 is distributed predominantly in south China and Southeast Asia and displays marked genetic diversity [2]. For instance, HCV-6 variants were reported in an outbreak from a low-resourced dialysis unit and were also common among patients undergoing dialysis in an epidemiological study in Vietnam [22, 23].

Giving high rates of transmission through parenteral routes, $\mathrm{HCV}$ infection in the community is mainly caused by high-risk behaviors, such as injecting drug users (IDU) and sexual practices [24]. In this respect, our previous report demonstrated that a high proportion of $\mathrm{HCV}$ mono-infected and HIV/HCV co-infected Thai patients had a history of IDU and being men who have sex with men (MSM)[25]. Previous Asia-Pacific registry data demonstrated that dialysis modality was an independent factor associated with $\mathrm{HCV}$ infection as higher rates of anti-HCV positivity were detected in patients undergoing HD compared with PD [26]. These results might reflect the cumulative risk of nosocomial infection over time, particularly in patients undergoing long-term dialysis vintage. Indeed, a recent meta-analysis in Asia populations also demonstrated a positive correlation between duration of HD and the risk of HCV infection [27]. For instance, patients with prolonged HD over 5 years were at increased risk of developing $\mathrm{HCV}$ infection six times higher than those with shorter HD duration, which was in line with this report.

The evidence of person-to-person transmission of $\mathrm{HCV}$ among patients in our cohort was further supported by phylogenetic analysis of the NS5B region. In this context, several studies showed that phylogenetic analysis of individual HCV RNA isolates could provide valuable information of nosocomial transmission of $\mathrm{HCV}$ occurring within dialysis units that might not be assessed through traditional epidemiological approaches [2830]. Our results identified 7 separate clusters of various $\mathrm{HCV}$ isolates involving 17 patients with high sequence homology to each other in distinct dialysis centers. These results emphasized the unrecognized $\mathrm{HCV}$ transmission within dialysis units might occur more frequently than anticipated due to asymptomatic or mild hepatitis among most infected individuals.

The KDIGO guidelines strongly recommend strict infection-control procedures in HD facilities, however, nosocomial transmission of $\mathrm{HCV}$ has been repeatedly observed, especially in low-, and middle-income countries [31]. Several potential risk factors and practices associated with patient-to-patient transmission have been proposed to explain such an increased risk of $\mathrm{HCV}$ infection, including dialyzer reuse, internal contamination of HD machines and contamination by staff members [9]. In this study, it was possible that $\mathrm{HCV}$ acquisition through dialysis machinery or by dialyzer reuse might be responsible for the small-scale outbreaks in infected individuals who shared the machine. Unfortunately, the exact mechanism of HCV transmission in each facility remains to be discovered and is currently under investigation. Similar to our report, a recent study from Vietnam demonstrated that sharing dialysis machines and environmental contamination might be contributable to an outbreak of $\mathrm{HCV}$ in a resource-limited HD unit [22]. Thus, strict adherence to standard infection control procedures regarding dialyzer reuse, disinfection of machines and hygienic precautions are highly needed [28]. In addition, regular screening for HCV infection is recommended for preventing $\mathrm{HCV}$ transmission within HD facilities [32].

The standard assessment for active $\mathrm{HCV}$ infection requires screening test with anti-HCV antibodies followed by the confirmation of NAT. However, HCV RNA testing is limited in developing countries due to high costs and the necessity of equipped laboratories. Serum $\mathrm{HCVcAg}$ has been shown to be an alternative assay to NAT due to its more practicability and less expensive. In the setting of low- and middle-income countries, World Health Organization (WHO) guidance recommends the utility of $\mathrm{HCVcAg}$ as an alternative test to diagnose $\mathrm{HCV}$ viremia when NAT is not accessible [33]. In this study, we directly compared the use of HCVcAg and HCV RNA measurement in patients with anti-HCV positivity. Our results showed that $\mathrm{HCVcAg}$ assay exhibited good performance and highly correlated with HCV RNA concentrations $(\mathrm{r}=0.955, P<0.001)$. Indeed, the correlation coefficients between the two markers in patients with ESRD were exceeding 0.90 in most previous reports [34, 35]. It should be mentioned that the correlation between both assays appeared to be high among patients with impaired immune response, including liver and kidney transplant recipients and patients with HIV co-infection $[36,37]$. Of note, of the three samples in this report that tested negative for $\mathrm{HCV}$ cAg, but were HCV RNA positive, all had low HCV RNA levels. This was in line with 
previous data indicating good correlation between both markers if viral load is greater than $3000 \mathrm{IU} / \mathrm{mL}$, the level of which is typically found in over $95 \%$ of untreated $\mathrm{HCV}$ individuals [33]. Given its high diagnostic accuracy and feasibility, we propose that $\mathrm{HCV} c \mathrm{Ag}$ testing could be used as a reliable biomarker of $\mathrm{HCV}$ viremia in guiding clinical decisions among patients with ESRD, particularly in resource-limited settings, where HCV RNA testing is not routinely available and cost-saving strategy is desirable.

A new paradigm of $\mathrm{HCV}$ treatment has improved considerably after the development of DAAs that specifically target viral replication in HCV life cycle [7]. Recent evidence has shown that HCV eradication or SVR can now be achieved in over $90 \%$ of patients with late-stage CKD treated with 12-week interferon-free DAA regimens [38, 39]. Growing evidence also supports the use of sofosbuvir-based regimens, which is safe and well tolerated, resulting in SVR rates of $97 \%$ in a meta-analysis of HCV-infected patients with ESRD [40]. Recent data have indicated that successful HCV therapy with DAAs can result in a decrease in liver-related complications and the incidence of $\mathrm{HCC}$, accompanied by an increased in overall survival rates[7]. In this cohort, approximately $10 \%$ of patients with HCV infection had significant fibrosis as assessed by APRI score. Without HCV treatment, these patients might eventually develop cirrhosis and liver-related complications. As benefits of $\mathrm{HCV}$ eradication with DAAs outweigh potential harm, it is now recommended that all HCV-infected patients with CKD should be evaluated for therapy according to KDIGO 2018 clinical practice guideline [10]. Another advantage of DAA therapy is that the risk of nosocomial transmission of $\mathrm{HCV}$ within $\mathrm{HD}$ facilities is likely to be reduced following treatment-as-prevention strategy. To this end, micro-elimination of $\mathrm{HCV}$ from HD units achieved by the combination of prevention and treatment is now considered as a realistic goal [41].

Based on the KDIGO guidelines [31], we proposed a simplified algorithm for HCV screening and management among patients undergoing HD, particularly in resource-limited settings (Fig. 2). Screening with anti$\mathrm{HCV}$ antibodies in patients with HD should be considered upon initiation of HD to document baseline HCV status. Among those with anti-HCV-positive, confirmation of viral replication through HCV RNA testing is required. Alternatively, serum $\mathrm{HCVcAg}$ could be used as a substitute test when HCV RNA quantification is not available and/or not affordable [12]. As liver biopsy is associated with an increased risk of procedure-related complications, non-invasive evaluation for staging of liver fibrosis such as serum biomarkers (e.g., APRI score) or liver stiffness measurement is also recommended for HCV-infected individuals [42]. According to the American Association for the Study of Liver Diseases and the Infectious Diseases Society of America (AASLD/IDSA) guidelines, all $\mathrm{HCV}$-infected patients should be considered for DAA treatment except for those with a limited life expectancy ( $<12$ months) due to liver disease or non-liver-related comorbid conditions [43]. The choice of specific DAA regimens is based on several factors including $\mathrm{HCV}$ genotype, prior treatment history, drug-drug interactions and comorbidities. If available, however, it is

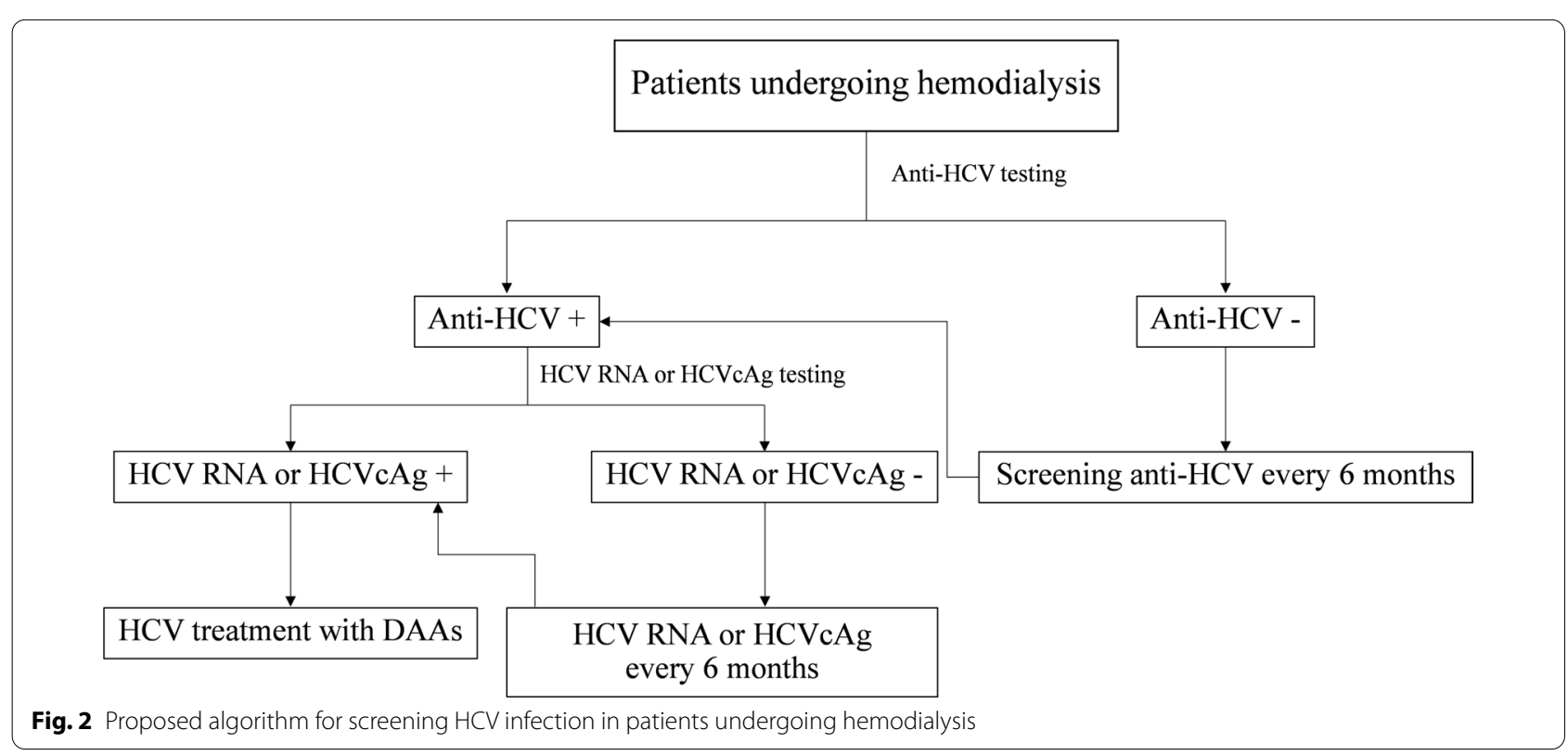


recommended to select pan-genotypic and ribavirinfree DAA regimens [43]. Patients who are not infected with HCV should be regularly screened for new infection using anti-HCV antibodies every 6 months. Finally, close collaboration between nephrologists and hepatologists is essential for effective diagnosis, prevention and treatment of $\mathrm{HCV}$ in patients with ESRD.

Although the practice of dialyzer reuse in developed countries such as in US, European Union countries, and Japan was discontinued, reuse dialyzer in resource-limited countries has been continuing and remains predominant in HD facilities. The need for dialyzer reuse is to balance the financial constrain of national health budget and accessibility of HD for patients with ESRD. The Kidney Disease Outcomes Quality Initiative (KDOQI) recommends that dialysis facilities choosing to reuse dialyzers must follow the Association for the Advancement of Medical Instrumentation (AAMI) recommendations for reprocessing [44]. Although dialyzer reuse has potential for nosocomial transmission of infection in HD facilities, a systematic review of 1176 studies in 956,807 patients demonstrated that there was no significant difference of patient's mortality between reused and non-reused dialyzer [45]. In Thailand, although there are trends to perform single use dialyzer among HD facilities, reuse of dialyzer is allowed if HIV antibody test is negative. For patients who test anti-HCV positive, the reuse of dialyzer could also be permitted but the reprocessing must be separated in isolated reuse facility and follow the AAMI recommendation. With addition of $\mathrm{HCVcAg}$ testing, we suggest that only single use dialyzer should be allowed in patients who test HCVcAg or HCV RNA positive.

There are some limitations in our study. First, we used the NS5B region for assessing HCV genotype distribution. In this context, previous data have indicated that the analysis of only this $\mathrm{HCV}$ region provides an accurate characterization of genotypes and sub-genotypes $[15,16]$. Second, it could be possible that other risk factors, such as IDU and MSM shared by infected patients, might be responsible for $\mathrm{HCV}$ transmission outside the HD centers. Finally, the approach of HCVcAg testing might has a decreased sensitivity in patients with low HCV RNA, which accounted for 5\% of individuals in our report. In fact, the probability of $\mathrm{HCV}$ contamination is considered to be insignificant in low level viremia. Additionally, HCVcAg quantification must be repeated at least semi-annually in patients with anti-HCV positivity based on our proposed algorithm (Fig. 2). Following this recommendation, the assay will be able to detect active infection if increasing viremia occurs in the natural course of chronic HCV infection.

\section{Conclusions}

This study indicated that HCV prevalence among Thai patients with ESRD remained high and its genotype distribution slightly differed to those of the general population. HCVcAg testing could be an alternative assay to HCV RNA in resource-limited settings. Our data based on phylogenetic analysis provided evidence supporting that patient-to-patient transmission of $\mathrm{HCV}$ occurred within HD units and indicate the importance of infection-control strategies. As patients with ESRD are increased risk of acquiring $\mathrm{HCV}$ infection via $\mathrm{HD}$, they should undergo regular screening and monitoring for the infection. In the era of highly effective DAAs, any HCVinfected patients should be considered for viral eradication therapy to reduce the risk of progressive liver disease as well as to prevent further viral transmission.

\section{Abbreviations \\ CKD: Chronic kidney disease; ESRD: End-stage renal disease; HCV: Hepatitis C virus; DAAs: Direct-acting antivirals; SVR: Sustained virological response; HD: Hemodialysis; IDU: Injecting drug users; MSM: Men who have sex with men; KDIGO: Kidney Disease: Improving Global Outcome; NAT: Nucleic acid testing; HCVcAg: Hepatitis C virus core antigen; HBV: Hepatitis B virus; HIV: Human immunodeficiency virus; AST: Aspartate aminotransferase; ALT: Alanine aminotransferase; APRI: AST/platelet ratio index; AASLD/IDSA: American Association for the Study of Liver Diseases and the Infectious Diseases Society of America (AASLD/IDSA); KDOQI: Kidney Disease Outcomes Quality Initiative; AAMI: Advancement of Medical Instrumentation.}

\section{Acknowledgements}

We would like to thank all the participants, who provided clinical data and biological specimens in this study: Sawat Petcharat, M.D., Panjapone Kobpungton, M.D., Kesara Chulaphan, Ruengrit Jinasen (Chiangrai Prachanukroh Hospital), Thanachai Panaput, M.D. Sarassawan Kananuraks, M.D, Jatuporn Phanprom (Khon Kaen Hospital), Wuttikorn Siriplabpla, M.D., Pornpana Saehan, Anothai Niam-in (Phrae Hospital), Thitima Saisut, M.D. (Detudom Royal Crown Prince Hospital), Thannawit Khamta (Prince Hospital) and Sajja Tatiyanupanwong, M.D., PhD, Apiruedee Intaraphol; Mekin Thinchaiyaphum; Nongluk Champee (Chaiyaphum Hospital).

\section{Authors' contributions}

KP and PT have contributed equally to this work as co-corresponding authors, who supervised and designed the research. NC and AK performed the experiments and analysis. NC carried out statistical analysis and interpretation. KP, TP, PS, WP, and AA performed sample and data collections. NC wrote the manuscript. KP and PT contributed to the final version of the manuscript. All authors read and approved the final manuscript.

\section{Funding}

The study was supported by The Thailand Research Fund (TRF) Senior Research Scholar (RTA6280004) and Center of Excellence in Hepatitis and Liver Cancer, Faculty of Medicine, Chulalongkorn University.

\section{Availability of data and materials}

The nucleotide sequences of NS5B gene were submitted to the GenBank database under accession numbers MT428260-MT428322.

\section{Declarations}

\section{Ethics approval and consent to participate}

All patients gave their informed written consent. The study was reviewed and approved by the Institutional Review Board, Faculty of Medicine, Chulalongkorn University. The study was performed in accordance with Declaration 
of Helsinki for the participation of human individuals. Information regarding demographic data were collected using a standardized questionnaire.

\section{Consent for publication}

Not applicable.

\section{Competing interests}

The authors declare that they have no competing interests.

\section{Author details}

${ }^{1}$ Center of Excellence in Hepatitis and Liver Cancer, Department of Biochemistry, Faculty of Medicine, Chulalongkorn University, Bangkok 10330, Thailand. ${ }^{2}$ Division of Gastroenterology, Department of Medicine, Faculty of Medicine, Chulalongkorn University, Bangkok, Thailand. ${ }^{3}$ Division of Nephrology, Department of Medicine, Faculty of Medicine, Chulalongkorn University and King Chulalongkorn Memorial Hospital, Bangkok, Thailand. ${ }^{4}$ Department of Disease Control, Bamrasnaradura Infectious Diseases Institute, Nonthaburi, Thailand. ${ }^{5}$ HIV-NAT, Thai Red Cross AIDS Research Centre, Bangkok, Thailand.

Received: 13 September 2021 Accepted: 17 January 2022 Published online: 22 January 2022

\section{References}

1. Spearman CW, Dusheiko GM, Hellard M, Sonderup M. Hepatitis C. Lancet. 2019;394(10207):1451-66. https://doi.org/10.1016/S0140-6736(19) 32320-7.

2. Smith DB, Bukh J, Kuiken C, Muerhoff AS, Rice CM, Stapleton JT, et al. Expanded classification of hepatitis $C$ virus into 7 genotypes and 67 subtypes: updated criteria and genotype assignment web resource. Hepatology. 2014;59(1):318-27. https://doi.org/10.1002/hep.26744.

3. Wasitthankasem R, Posuwan N, Vichaiwattana P, Theamboonlers A, Klinfueng S, Vuthitanachot $V$, et al. Decreasing hepatitis C virus infection in Thailand in the past decade: evidence from the 2014 national survey. PLoS ONE. 2016;11(2): e0149362. https://doi.org/10.1371/journal.pone. 0149362.

4. Hajarizadeh B, Grebely J, Dore GJ. Epidemiology and natural history of HCV infection. Nat Rev Gastroenterol Hepatol. 2013;10(9):553-62.

5. Fabrizi F, Verdesca S, Messa P, Martin P. Hepatitis C virus infection increases the risk of developing chronic kidney disease: a systematic review and meta-analysis. Dig Dis Sci. 2015;60(12):3801-13. https://doi.org/10.1007/ s10620-015-3801-y.

6. Pol S, Parlati L, Jadoul M. Hepatitis C virus and the kidney. Nat Rev Nephrol. 2019;15(2):73-86. https://doi.org/10.1038/s41581-018-0081-8.

7. Ioannou GN, Feld JJ. What are the benefits of a sustained virologic response to direct-acting antiviral therapy for hepatitis $C$ virus infection? Gastroenterology. 2019;156(2):446-60.e2. https://doi.org/10.1053/j.gastro. 2018.10.033.

8. Nguyen DB, Bixler D, Patel PR. Transmission of hepatitis C virus in the dialysis setting and strategies for its prevention. Semin Dial. 2019;32(2):12734. https://doi.org/10.1111/sdi.12761.

9. Fabrizi F, Messa P. The epidemiology of HCV infection in patients with advanced CKD/ESRD: a global perspective. Semin Dial. 2019;32(2):93-8. https://doi.org/10.1111/sdi.12757.

10. Kidney Disease: Improving Global Outcomes Hepatitis CWG. KDIGO 2018 clinical practice guideline for the prevention, diagnosis, evaluation, and treatment of hepatitis c in chronic kidney disease. Kidney Int Suppl. 2018;8(3):91-165. https://doi.org/10.1016/j.kisu.2018.06.001.

11. Freiman JM, Tran TM, Schumacher SG, White LF, Ongarello S, Cohn J, et al. Hepatitis $C$ core antigen testing for diagnosis of hepatitis $C$ virus infection: a systematic review and meta-analysis. Ann Intern Med. 2016;165(5):345-55. https://doi.org/10.7326/M16-0065.

12. van Tilborg M, Al Marzooqi SH, Wong WWL, Maan R, Vermehren J, Maasoumy B, et al. HCV core antigen as an alternative to HCV RNA testing in the era of direct-acting antivirals: retrospective screening and diagnostic cohort studies. Lancet Gastroenterol Hepatol. 2018;3(12):856-64. https:// doi.org/10.1016/S2468-1253(18)30271-1.

13. Lin ZH, Xin YN, Dong QJ, Wang Q, Jiang XJ, Zhan SH, et al. Performance of the aspartate aminotransferase-to-platelet ratio index for the staging of hepatitis C-related fibrosis: an updated meta-analysis. Hepatology. 2011;53(3):726-36. https://doi.org/10.1002/hep.24105.

14. Murayama A, Sugiyama N, Watashi K, Masaki T, Suzuki R, Aizaki H, et al. Japanese reference panel of blood specimens for evaluation of hepatitis $\mathrm{C}$ virus RNA and core antigen quantitative assays. J Clin Microbiol. 2012;50(6):1943-9. https://doi.org/10.1128/JCM.00487-12.

15. Nie B, Zhang G, Guo Y, Li Q, Liu J, Tu Z. Phylogenetic analysis of HCV subgenotypes in patients from Sichuan province in China based on the NS5B region. Int J Mol Med. 2015;36(4):1028-34. https://doi.org/10.3892/ijmm. 2015.2321.

16. El Hadad S, Al-Hamdan H, Linjawi S. Partial sequencing analysis of the NS5B region confirmed the predominance of hepatitis $C$ virus genotype 1 infection in Jeddah, Saudi Arabia. PLoS ONE. 2017;12(5): e0178225. https://doi.org/10.1371/journal.pone.0178225.

17. Kimura M. A simple method for estimating evolutionary rates of base substitutions through comparative studies of nucleotide sequences. J Mol Evol. 1980;16(2):111-20. https://doi.org/10.1007/BF01731581.

18. Ramière $C$, Charre $C$, Miailhes $P$, Bailly F, Radenne $S$, Uhres AC, Brochier C, Godinot M, Chiarello P, Pradat P, Cotte L, Lyon Acute Hepatitis Study Group. Patterns of Hepatitis C Virus Transmission in Human Immunodeficiency Virus (HIV)-infected and HIV-negative Men Who Have Sex With Men. Clin Infect Dis. 2019;69(12):2127-35. https://doi.org/10.1093/cid/ ciz160.

19. Li PK, Bavanandan S, Mohamed R, Szeto CC, Wong VW, Chow KM, et al. 2018 kidney disease: improving global outcomes (KDIGO) Hepatitis C in chronic kidney disease guideline implementation: Asia Summit Conference Report. Kidney Int Rep. 2020;5(8):1129-38. https://doi.org/10.1016/j. ekir.2020.05.001.

20. Akkarathamrongsin S, Hacharoen P, Tangkijvanich $P$, Theamboonlers A, Tanaka Y, Mizokami M, et al. Molecular epidemiology and genetic history of hepatitis C virus subtype 3a infection in Thailand. Intervirology. 2013;56(5):284-94. https://doi.org/10.1159/000351621.

21. Fabrizi F, Dulai G, Dixit V, Bunnapradist S, Martin P. Meta-analysis: interferon for the treatment of chronic hepatitis $C$ in dialysis patients. Aliment Pharmacol Ther. 2003;18(11-12):1071-81. https://doi.org/10.1046/j.13652036.2003.01780.x.

22. Duong CM, McLaws ML. An investigation of an outbreak of hepatitis C virus infections in a low-resourced hemodialysis unit in Vietnam. Am J Infect Control. 2016;44(5):560-6. https://doi.org/10.1016/j.ajic.2016.01. 014.

23. Dunford L, Carr MJ, Dean J, Waters A, Nguyen LT, Ta Thi TH, et al. Hepatitis $C$ virus in Vietnam: high prevalence of infection in dialysis and multitransfused patients involving diverse and novel virus variants. PLOS ONE. 2012;7(8): e41266. https://doi.org/10.1371/journal.pone.0041266.

24. Lanini S, Easterbrook PJ, Zumla A, Ippolito G. Hepatitis C: global epidemiology and strategies for control. Clin Microbiol Infect. 2016;22(10):833-8. https://doi.org/10.1016/j.cmi.2016.07.035.

25. Avihingsanon A, Jitmitraparp S, Tangkijvanich P, Ramautarsing RA, Apornpong T, Jirajariyavej S, et al. Advanced liver fibrosis by transient elastography, fibrosis 4, and alanine aminotransferase/platelet ratio index among Asian hepatitis $C$ with and without human immunodeficiency virus infection: role of vitamin D levels. J Gastroenterol Hepatol. 2014;29(9):1706-14. https://doi.org/10.1111/jgh.12613.

26. Johnson DW, Dent H, Yao Q, Tranaeus A, Huang CC, Han DS, et al. Frequencies of hepatitis $B$ and $C$ infections among haemodialysis and peritoneal dialysis patients in Asia-Pacific countries: analysis of registry data. Nephrol Dial Transplant. 2009;24(5):1598-603. https://doi.org/10. 1093/ndt/gfn684

27. Cai G, Zheng H, Luo L, Wang Z, Jiang Z, Xu S, et al. Factors correlating to the development of hepatitis $C$ virus infection in hemodialysis patientsfindings mainly from asiatic populations: a systematic review and metaanalysis. Int J Environ Res Public Health. 2019. https://doi.org/10.3390/ ijerph16081453.

28. Kokubo S, Horii T, Yonekawa O, Ozawa N, Mukaide M. A phylogenetic-tree analysis elucidating nosocomial transmission of hepatitis $C$ virus in a haemodialysis unit. J Viral Hepatitis. 2002;9(6):450-4. https://doi.org/10. 1046/j.1365-2893.2002.00374.X.

29. Abacioglu YH, Bacaksiz F, Bahar IH, Simmonds P. Molecular evidence of nosocomial transmission of hepatitis C virus in a haemodialysis unit. Eur J Clin Microbiol Infect Dis. 2000;19(3):182-6. https://doi.org/10.1007/s1009 60050456. 
30. Garvey MI, Bradley CW, Holden KL, Hewins P, Ngui SL, Tedder R, et al. Use of genome sequencing to identify hepatitis $C$ virus transmission in a renal healthcare setting. J Hosp Infect. 2017;96(2):157-62. https://doi.org/10. 1016/j.jhin.2017.01.002.

31. Jadoul M, Berenguer MC, Doss W, Fabrizi F, Izopet J, Jha V, et al. Executive summary of the 2018 KDIGO Hepatitis C in CKD Guideline: welcoming advances in evaluation and management. Kidney Int. 2018;94(4):663-73. https://doi.org/10.1016/j.kint.2018.06.011.

32. Gordon CE, Berenguer MC, Doss W, Fabrizi F, Izopet J, Jha V, et al. Prevention, diagnosis, evaluation, and treatment of hepatitis $C$ virus infection in chronic kidney disease: synopsis of the kidney disease: improving global outcomes 2018 clinical practice guideline. Ann Intern Med. 2019. https:// doi.org/10.7326/M19-1539.

33. Easterbrook PJ, Group WHOGD. Who to test and how to test for chronic hepatitis C infection-2016 WHO testing guidance for low- and middleincome countries. J Hepatol. 2016;65(1 Suppl):S46-66. https://doi.org/10. 1016/j.jhep.2016.08.002.

34. Mederacke I, Potthoff A, Meyer-Olson D, Meier M, Raupach R, Manns MP, et al. HCV core antigen testing in HIV- and HBV-coinfected patients, and in HCV-infected patients on hemodialysis. J Clin Virol. 2012;53(2):110-5. https://doi.org/10.1016/j.jcv.2011.11.009.

35. Miedouge M, Saune K, Kamar N, Rieu M, Rostaing L, Izopet J. Analytical evaluation of HCV core antigen and interest for HCV screening in haemodialysis patients. J Clin Virol. 2010;48(1):18-21. https://doi.org/10.1016/j. jcv.2010.02.012.

36. Heidrich B, Pischke S, Helfritz FA, Mederacke I, Kirschner J, Schneider J, et al. Hepatitis $C$ virus core antigen testing in liver and kidney transplant recipients. J Viral Hepat. 2013. https://doi.org/10.1111/jvh.12204.

37. Thong VD, Akkarathamrongsin S, Avihingsanon A, Theamboonlers A, Poovorawan Y, Tangkijvanich P. The correlation between hepatitis $C$ core antigen and hepatitis $C$ virus RNA levels with respect to human immunodeficiency virus status, hepatitis $C$ virus genotype and interferonlambda-4 polymorphism. Intervirology. 2015;58(2):73-9. https://doi.org/ 10.1159/000370070

38. Gane E, Lawitz E, Pugatch D, Papatheodoridis G, Brau N, Brown A, et al. Glecaprevir and pibrentasvir in patients with $\mathrm{HCV}$ and severe renal impairment. N Engl J Med. 2017;377(15):1448-55. https://doi.org/10. 1056/NEJMoa1704053.

39. Roth D, Nelson DR, Bruchfeld A, Liapakis A, Silva M, Monsour H Jr, et al. Grazoprevir plus elbasvir in treatment-naive and treatment-experienced patients with hepatitis $C$ virus genotype 1 infection and stage 4-5 chronic kidney disease (the C-SURFER study): a combination phase 3 study. Lancet. 2015;386(10003):1537-45. https://doi.org/10.1016/S01406736(15)00349-9.

40. Saxena V, Koraishy FM, Sise ME, Lim JK, Schmidt M, Chung RT, et al. Safety and efficacy of sofosbuvir-containing regimens in hepatitis $C$-infected patients with impaired renal function. Liver Int. 2016;36(6):807-16. https://doi.org/10.1111/liv.13102.

41. Jadoul $M$, Horsmans $Y$. Towards eradication of hepatitis $C$ virus from dialysis units. Lancet. 2015;386(10003):1514-5. https://doi.org/10.1016/ S0140-6736(15)00381-5.

42. Castera L. Noninvasive methods to assess liver disease in patients with hepatitis B or C. Gastroenterology. 2012;142(6):1293-302.e4. https://doi. org/10.1053/j.gastro.2012.02.017.

43. Panel A-IHG. Hepatitis C quidance 2018 update: AASLD-IDSA recommendations for testing, managing, and treating hepatitis $\mathrm{C}$ virus infection. Clin Infect Dis. 2018;67(10):1477-92. https://doi.org/10.1093/cid/ciy585.

44. Clinical Practice Guidelines and Clinical Practice Recommendations 2006 Updates. http://kidneyfoundation.cachefly.net/professionals/KDOQI/ guideline_upHD_PD_VA/index.htm. Accessed 26 Nov 2021.

45. Galvao TF, Silva MT, Araujo ME, Bulbol WS, Cardoso AL. Dialyzer reuse and mortality risk in patients with end-stage renal disease: a systematic review. Am J Nephrol. 2012;35(3):249-58. https://doi.org/10.1159/00033 6532

\section{Publisher's Note}

Springer Nature remains neutral with regard to jurisdictional claims in published maps and institutional affiliations.

Ready to submit your research? Choose BMC and benefit from:

- fast, convenient online submission

- thorough peer review by experienced researchers in your field

- rapid publication on acceptance

- support for research data, including large and complex data types

- gold Open Access which fosters wider collaboration and increased citations

- maximum visibility for your research: over 100M website views per year

At BMC, research is always in progress.

Learn more biomedcentral.com/submissions 